\title{
DUKUNGAN KELUARGA DALAM MERAWAT ANAK DENGAN THALASSEMIA BETA MAYOR
}

\author{
Rezka Nurvinanda ${ }^{1}$, Sri Mulatsih ${ }^{2}$, Sri Hartini ${ }^{3}$, Intansari Nurjannah ${ }^{4}$ \\ ${ }^{1,3,4}$ Program Studi Magister Keperawatan, Universitas Gajah Mada, Yogyakarta \\ ${ }^{2}$ Rumah Sakit Umum Pusat Dr. Sardjito, Yogyakarta \\ Email: rezka_nurvinanda@stikescitradelima.ac.id \\ ABSTRAK
}

Pendahuluan: Salah satu penyakit kronis yang diderita anak adalah thalassemia. Thalassemia adalah kelainan darah yang diturunkan secara genetik, ditandai dengan adanya penurunan sintesis rantai globin dalam hemoglobin. Thalassemia menjadi masalah kesehatan yang serius di seluruh wilayah Mediterania, Timur Tengah, India, dan Asia Tenggara, termasuk Indonesia yang memiliki penduduk pembawa gena thalassemia dengan frekuensi sebesar 3-8\%. Anak thalassemia beta mayor harus menjalani pengobatan dalam jangka waktu yang panjang sehingga memberikan dampak bagi anak dan keluarga. Manajemen keperawatan untuk anak dengan thalassemia mayor berpusat pada pengajaran keluarga dan dukungan keluarga. Penelitian ini bertujuan untuk mengekplorasi tentang dukungan keluarga dalam merawat anak dengan thalassemia beta mayor.

Metode: Penelitian ini menggunakan desain kualitatif dengan pendekatan fenomenologi. Partisipan dipilih dengan menggunakan teknik purposive sampling dan didapatkan 8 partisipan yang merupakan ibu sebagai caregiver utama dalam merawat anak dengan thalassemia beta mayor. Penelitian ini menggunakan tehnik pengumpulan data dengan wawancara mendalam, kemudian data dianalisis menggunakan metode Colaizzi.

Hasil: Berdasarkan pengalaman yang disampaikan oleh partisipan selama merawat anak dengan thalassemia beta mayor, peneliti menemukan 2 subtema dari tema dukungan bagi keluarga, yaitu dukungan internal keluarga dan dukungan eksternal.

Kesimpulan: Dukungan bagi keluarga selama merawat anak dengan thalassemia beta mayor didapatkan atau tersedia bagi keluarga, baik dukungan dari internal dan eksternal dalam bentuk dukungan instrumental, emosional, informasi serta finansial.

Kata Kunci: Dukungan Keluarga, Anak, Thalassemia

\section{Family Support in Caring For Children with Thalassemia Beta Major}

Background: One of the chronic diseases suffered by children is thalassemia. Thalassemia is a genetically inherited blood disorder characterized by a decrease in the synthesis of globin chains in hemoglobin. Thalassemia is a serious health problem throughout the Mediterranean region, Middle East, India and Southeast Asia, including Indonesia which has a population carrying thalassemia with a frequency of 3-8\%. Children with major beta thalassemia must undergo treatment for a long period of time to have an impact on children and families. Nursing management for children with major thalassemia centers on family teaching and family support. This study aims to explore family support in treating children with major beta thalassemia.

Method: This study uses a qualitative design with a phenomenological approach. Participants were selected using a purposive sampling technique and obtained 8 participants who were mothers as the primary caregiver in treating children with major beta thalassemia. This study uses data collection techniques with in-depth interviews, then the data are analyzed using the Colaizzi method.

Result: Based on the experience conveyed by the participants while caring for children with major beta thalassemia, researchers found 2 sub-themes from the theme of support for the family, namely internal family support and external support.

Conclusion: Support for families while caring for children with major beta thalassemia is obtained or available to families, both from internal and external support in the form of instrumental, emotional, information and financial support.

Keyword: Family Support, Children, Thalassemia

\section{A. PENDAHULUAN}

Penyakit kronis merupakan suatu kondisi yang menyebabkan anak menjalani rawat inap minimal selama satu bulan dalam satu tahun karena anak umumnya mendapatkan pengobatan rutin dalam jangka waktu yang lama (Hockenberry \& Wilson, 2011). Salah satu penyakit kronis yang diderita anak adalah thalassemia. Thalassemia adalah kelainan darah yang diturunkan secara genetik, ditandai 
dengan adanya penurunan sintesis rantai globin dalam hemoglobin (Surapolchai et al., 2010). Thalassemia menjadi masalah kesehatan yang serius di seluruh wilayah Mediterania, Timur tengah, India, dan Asia Tenggara (Baghianimoghadam et al., 2011). Indonesia juga termasuk salah satu negara yang memiliki penduduk pembawa gena thalassemia dengan frekuensi sebesar 3-8\% yang berarti bahwa 3-8 dari 100 penduduk merupakan pembawa gena thalassemia (Mariani, 2011).

Anak dengan thalassemia mayor harus menjalani dan membutuhkan transfusi darah secara terus-menerus yang berpotensi menimbulkan komplikasi akibat penimbunan zat besi di dalam tubuh. Hal ini menyebabkan anak harus mendapatkan terapi kelasi besi secara teratur dengan tujuan utama untuk mempertahankan kadar besi yang aman di dalam tubuhnya (Capellini et al., 20014). Proses pengobatan thalassemia memberikan dampak bagi anak dan orang tua. Dampak bagi orang tua terkait dengan perawatan anak dengan thalassemia adalah bertambahnya beban dalam hal waktu, tenaga, pekerjaan, dan masalah finansial (Wong et al., 2009).

Penelitian kualitatif tentang pengalaman ibu merawat anak dengan thalassemia di Yunani juga menemukan bahwa orangtua merasa syok, distress dan menunjukkan penolakan saat mengetahui anaknya terdiagnosa thalassemia. Para ibu juga merasa cemas dan takut selama perawatan dan pengobatan sehingga dukungan dari suami dan keluarga serta tenaga profesional sangat dibutuhkan (Sapountzi-Krepia et al., 2006).

Penelitian ini bermaksud untuk mengeksplorasi pengalaman keluarga dalam merawat anak dengan thalassemia secara lebih mendalam dari beberapa aspek yang telah disusun peneliti sebagai tujuan penelitian. Hasil penelitian yang dilakukan, diharapkan akan dapat memberikan informasi mengenai pengalaman orangtua dalam merawat anak dengan thalassemia serta memperoleh gambaran permasalahan yang dihadapi anak dan keluarga sehingga dapat membuat perencanaan dalam pemberian pelayanan kesehatan secara adekuat dan holistik.

\section{B. METODE PENELITIAN}

Penelitian ini menggunakan desain kualitatif, yaitu penelitan yang menggunakan pendekatan fenomenologi untuk mencari pemahaman tentang fenomena mengenai apa yang dialami oleh subjek penelitian, dengan cara menggambarkan dalam bentuk kata-kata dan bahasa pada suatu latar yang berkonteks khusus dan alamiah (Moleong, 2014).

Partisipan dipilih dengan menggunakan teknik purposive sampling, yaitu pemilihan para calon partisipan berdasarkan kepemilikan kekayaan informasi tentang pengalaman khusus atau tertentu dengan tujuan saling berbagi pengalaman atau pengetahuan tentang fenomena yang diteliti (Afiyanti dan Rachmawati, 2014). Partisipan dalam penelitian ini adalah ibu yang mempunyai anak dengan thalassemia dan berperan sebagai caregiver utama bagi anak. mampu berkomunikasi secara baik dan jelas, serta bersedia menjadi partisipan. Sebanyak 8 orang ibu bersedia berpartisipasi dalam penelitian ini.

Penelitian ini telah lulus uji kelayakan etik dari komite etik FK UGM dengan nomor surat KE/FK/1382/EC. Dalam penelitian ini, peneliti juga memperhatikan prinsip-prinsip etik untuk melindungi hak-hak partisipan. Beberapa prinsip etik yang digunakan dalam penelitian ini, yaitu, beneficence, menghargai martabat manusia, dan justice. Peneliti memperhatikan kemanfaatan (beneficence) dari penelitian yang dilakukan dengan meminimalkan resiko (nonmaleficence) dari kegiatan penelitian agar tidak membahayakan partisipan (free from harm) dan melindungi partisipan dari ketidaknyamanan (free from discomfort), serta terbebas dari eksploitasi apapun (free from exploitation).

Penelitian ini menggunakan tehnik pengumpulan data dengan wawancara mendalam (indepth interview). Pedoman wawancara yang digunakan dalam penelitian ini menggunakan wawancara semiterstruktur. Pada saat pengumpulan data, peneliti menggunakan perekam, yaitu voice recorder sebagai alatbantu untuk merekam informasi yang disampaikan partisipan dan dilengkapi juga dengan catatan lapangan.

Peneliti melakukan wawancara di beberapa kabupaten di wilayah Pulau Bangka. Hasil wawancara dibuatkan transkip verbatim dan dilakukan analisis dengan metode Colaizzi. 


\section{HASIL}

Delapan orang partisipan dalam penelitian ini berusia 28-50 tahun, beragama Islam, suku Melayu dengan tingkat pendidikan mulai dari SD sampai S1.

Dukungan keluarga selama merawat anak dengan thalassemia beta mayor didapatkan, baik internal dan eksternal. Dukungan keluarga merujuk pada dukungan sosial yang dirasakan oleh anggota keluarga dalam bentuk hubungan yang dapat diakses atau tersedia bagi keluarga, baik dukungan dari internal maupun eksternal keluarga (Friedman et al., 2013). Segala bentuk dukungan yang didapatkan seperti dukungan instrumental, penilaian, informasi, emosional, maupun finansial memberikan manfaat yang besar bagi keluarga, terutama bagi ibu dalam merawat anak dengan thalassemia.

Keterlibatan keluarga dalam perawatan akan meningkatkan hasil perawatan yang optimal daripada perawatan yang hanya dilakukan secara individu saja. Pasangan atau suami adalah orang yang paling terdekat bagi ibu dibandingkan saudara atau keluarga yang lainnya, 3 dari 7 partisipan yang mempunyai pasangan menyampaikan bahwa bersama pasangan saling mendukung satu sama lain dan bersama-sama saling membantu dalam merawat anak yang menderita thalassemia beta mayor, adapun ungkapan partisipan sebagai berikut:

“...,tapi sekarang kek papa e kite saling berbagi ape, kerjasame lah ok, saling dukung supaya anak bise sembuh" (P5)

"kadang kami bedue lah bawa e...same-same kite ngurus anak ken” (P8)

Berdasarkan hasil triangulasi dukungan yang diberikan pasangan atau suami kepada ibu, seperti menenangkan dan menguatkan ibu untuk menghadapi dan menjalani semuanya, serta berusaha bersama-sama melakukan perawatan demi kesehatan anak-anak dan keluarga, pernyataan dari partisipan sebagai berikut:

“...nenanggin ibu e, nguatin ibu juga, kite berusahalah same-same biar anak sehat terus, same-same ke rumah sakit e," (P10)

Seluruh partisipan juga mendapatkan dukungan dari keluarga yang lain, seperti orangtua kandung, mertua, dan saudara yang lain. Bentuk dukungan yang diberikan baik itu dukungan emosional, informasi, instrumental dan finansial, seperti yang diungkapkan oleh partisipan berikut ini:

"Pinjem-pinjem lah uangnya sama ibu saya atau adek-adek saya buat transfusi itu" (P1)

"seperadik-seperadik (saudara-saudara) ge kasihan kek die, perhatian ge, kelak ditanya "nek gi berobat ok ke pengkal", aok kate kami, sabar, ati-ati, dijage anak e cemtu.." (P7)

Dukungan dari teman juga berarti bagi partisipan, terutama bagi 2 partisipan yang juga bekerja membantu mencari nafkah demi keluarga. Tanggungjawab untuk mendampingi anak menjalani pengobatan rutin ke rumah sakit membuat ibu harus meminta izin setiap bulannya, akan tetapi karena semua temanteman sudah mengetahui dengan jelas kondisi kesehatan anak sehingga mereka selalu mengerti dan memberikan dukungan bagi partisipan agar dapat merawat anaknya yang menderita thalassemia beta mayor dengan baik. Pernyataan partisipan adalah sebagai berikut:

"Di kantor saya bekerja itu, mereka sudah tahu kok anak saya sakit, jadi mereka gak marahlah kalau anak kita sakit...mereka mengerti.” (P1)

"ibarat e alhamdulillah untuk support dari kawan-kawan, alhamdulillah lah kalau untuk rekan-rekan, kepala sekolah, ibarat e ken mengerti" (P5)

Kemudian dukungan yang diberikan oleh tenaga kesehatan, seperti memberikan informasi awal tentang apa itu thalassemia beta mayor, informasi tentang jaminan kesehatan, serta memberikan perawatan kepada anak dengan cukup baik saat di rumah sakit. Meskipun demikian partisipan menyampaikan bahwa dukungan tersebut masih dirasakan kurang karena keluarga mengatakan tidak pernah mendapatkan pendidikan kesehatan spesifik terkait penyakit thalassemia dan cara perawatannya yang diharapkan dapat diberikan secara berkelanjutan karena sangat dibutuhkan bagi orangtua dan keluarga untuk dapat melakukan perawatan anak dengan thalassemia beta mayor. Adapun pernyataan yang disampaikan oleh partisipan sebagai berikut:

“...,dokter lah udeh e ngasih tahu kalau thalassemia tuh penyakit kelebihan sel darah putih jadi anak ibu nek ditransfusi terus setiap bulan e, cemtu kate e.” (P8) 
"Respon dari bendorang sih cepet lah karena untuk thalassemia sih diutamakan lah, kalau untuk ruangan atau apa tetep disediakan untuk thalassemia...” (P3)

"Aoklah nek be pasti e ok, men ade penyuluhan cemtu ken kita pacak nambah pengalaman kan, biar anak e sape tahu sehat...jadi ade harapan macem tuh tapi kite nunggu lah sape tahu kelak ade ken.” (P6)

Selain itu, berdasarkan hasil wawancara dengan partisipan juga diketahui bahwa POPTI (Perhimpunan Orangtua Penderita Thalassemia Indonesia) yang dibentuk pada tanggal 23 September 2013, dan pada saat acara pembentukan tersebut diadakan juga kegiatan penyuluhan atau pemberian informasi tentang thalassemia dengan pembicara sumber dari YTI (Yayasan Thalassemia Indonesia) pusat, dan juga adanya sharing pengalaman dari anak-anak thalassemia yang mampu mencapai usia remaja dan dewasa sebagai motivasi bagi para orangtua yang mempunyai anak thalassemia. Setahun kemudian, POPTI baru mengadakan acara kembali, tetapi hanya sekedar family gathering bagi para orangtua dan anak-anak thalassemia tanpa adanya kegiatan penyuluhan atau pendidikan kesehatan, dan hingga saat ini tidak pernah ada lagi kegiatan maupun pertemuan yang dilakukan. Oleh karena itu, dapat dikatakan bahwa POPTI cabang Pangkalpinang belum berjalan dan berfungsi dengan maksimal.

\section{PEMBAHASAN}

Dukungan keluarga adalah suatu proses yang terjadi sepanjang masa kehidupan dengan sifat dan bentuk dukungan yang berbeda pada masing-masing tahap siklus kehidupan (Friedman et al., 2013). Dukungan keluarga menjadi salah satu sistem pendukung bagi keluarga untuk dapat memberikan perawatan kepada anggota keluarga yang mengalami gangguan kesehatan secara optimal.

Individu yang berada dalam lingkungan sosial yang suportif memiliki kondisi kesehatan dan perkembangan yang lebih baik. Dukungan sosial dapat berfungsi sebagai pencegahan untuk mengurangi stresor dan respon negatif sehingga dapat meningkatkan kesehatan mental individu atau keluarga secara langsung. Bagi keluarga yang mempunyai anak penyandang thalassemia beta mayor, dukungan sosial merupakan kekuatan bagi keluarga agar terus mampu memberikan asuhan yang komprehensif, dan pada umumnya anggota keluarga yang mengemban peran pemberi asuhan dalam keluarga adalah seorang wanita. Ibu adalah pemberi asuhan primer bagi anak yang sakit kronik (Shepard dan Mahon, 1996 dalam Friedman et al., 2013).

Dukungan keluarga dapat berasal dari berbagai sumber yang berbeda, baik internal maupun eksternal, seperti pasangan, saudara, teman, rekan kerja, tenaga kesehatan atau organisasi masyarakat (Potter dan Perry, 2005). Hasil penelitian ini ditemukan bahwa selama merawat anak dengan thalassemia, partisipan mendapatkan dukungan dari suami, orangtua, saudara, teman, tenaga kesehatan, dan juga pemerintah. Meskipun ibu berperan sebagai pemberi asuhan primer, pasangan atau suami juga mempunyai andil besar dalam proses tersebut. Pasangan atau suami adalah orang terdekat bagi partisipan untuk dapat bersama-sama saling memberikan dukungan dan membantu dalam merawat anak yang menderita thalassemia. Memiliki kualitas hubungan yang baik antara suami istri merupakan hal yang penting dalam menghadapi dampak penyakit kronis anak bagi orang tua (Asyanti, 2013). Seorang suami dapat memberikan dukungan finansial, sosial, dan membantu tugas instrumental, serta praktik kesehatan akan meningkat saat suami secara aktif terlibat dalam urusan internal keluarga termasuk yang berkaitan dengan sistem pelayanan kesehatan (Friedman et al., 2013).

Penelitian ini juga menemukan bahwa partisipan juga mendapatkan dukungan dari keluarga yang lain seperti orangtua, ibu mertua, dan juga saudara yang lain, baik itu dukungan emosional, instrumental, penilaian, informasi, dan juga finansial. Sejalan dengan penelitian Sapountzi-Krepia et al., (2006) bahwa ibu mendapatkan dukungan emosional dan dukungan instrumental dari suami dan keluarga yang lain, seperti ibu kandung, ibu mertua, saudara kandung dan ipar selama memberikan perawatan kepada anak yang menderita thalassemia.

Orangtua dari anak dengan penyakit kronis, terutama ibu, merasa tidak beruntung dalam masyarakat mungkin karena tantangan untuk menyeimbangkan antara kebutuhan 
perawatan anak dengan pekerjaan dan ketersediaan waktu luang (Hatzmann et al., 2014). Pada penelitian ini partisipan merasakan bahwa dukungan dari rekan kerja, teman dan sesama orangtua dari anak thalassemia sangat berarti. Bagi 2 orang partisipan yang bekerja, mereka harus meminta izin setiap 2 minggu atau sebulan sekali untuk membawa anak berobat ke rumah sakit sehingga bentuk pengertian dan dukungan yang didapatkan dari rekan kerja tersebut memotivasi dan menguatkan partisipan untuk dapat terus merawat anaknya dengan baik. Perasaan senasib dengan orangtua anak thalassemia beta mayor yang lain membuat mereka saling memberikan dukungan emosional, saling bertukar informasi dan berbagi pengalaman selama merawat anak thalassemia beta mayor. Hasil penelitian ini sejalan dengan penelitian Indriati (2011) bahwa tetangga, teman, dan orangtua anak thalassemia beta mayor lainnya mempunyai peran yang penting dalam pertukaran informasi dan pengalaman tentang perawatan anak masing-masing, serta ibu juga tidak merasa sendiri saja yang mempunyai dan merawat anak dengan thalassemia beta mayor. Keluarga dengan tingkat komunikasi dan pertukaran informasi yang lebih baik dapat beradaptasi atau dapat mengatasi masalah yang dihadapi dengan baik didalam keluarga (McCubbin dan McCubbin, 1991 dalam Friedman et al, 2013).

Penelitian ini juga menemukan bahwa dukungan dari tenaga kesehatan sangat dibutuhkan bagi para orangtua dari anak thalassemia beta mayor, seperti menjadi sumber dan pemberi informasi yang utama, memberikan dukungan emosional dimana tenaga kesehatan khususnya perawat dapat berkunjung lebih sering, dapat memahami perasaan dan kekhawatiran para orangtua selama berada di rumah sakit, serta memberikan pelayanan kesehatan secara optimal. Penelitian oleh Arbabisarjou et al., (2014) ditemukan bahwa adanya ketidakpuasan para orangtua karena kurangnya kunjungan dan tidak adekuatnya pengajaran yang didapatkan oleh orangtua dan pasien thalassemia dari dokter dan tenaga kesehatan yang lain. Dukungan profesional yang tepat dapat membantu mengurangi stress dan memfasilitasi koping melalui pemberian informasi yang adekuat, dukungan emosional, dan bantuan finansial (Ahmad dan Atkin, 1996 dalam Rachmaniah, 2012).

\section{E. KESIMPULAN DAN SARAN Kesimpulan}

Selama merawat anak dengan thalassemia beta mayor, keluarga mendapatkan dukungan, baik dari internal maupun eksternal keluarga, yaitu dukungan dari suami, orangtua, saudara, teman, rekan kerja, dan tenaga kesehatan. Bentuk dukungan yang didapatkan antara lain, yaitu dukungan emosional, informasi, instrumental, serta finansial.

\section{Saran}

Hasil penelitian ini diharapkan dapat menjadi sumber informasi bagi perawat agar dapat lebih memberikan perhatian dan dukungan kepada keluarga dari anak thalassemia, serta melakukan pendekatan yang lebih baik kepada keluarga sehingga dapat mengkaji kebutuhan keluarga selama memberikan perawatan terhadap anak. Meningkatkan pelayanan keperawatan melalui program penyuluhan dan edukasi yang diberikan secara komprehensif untuk meningkatkan pengetahuan ibu dalam merawat anak dengan thalassemia beta mayor. Bagi penelitian selanjutnya, hasil penelitian ini dapat digunakan sebagai data untuk mengembangkan penelitian lebih lanjut yang difokuskan pada salah satu atau beberapa aspek yang lebih spesifik sehingga dapat menentukan pendekatan yang lebih efektif dalam memberikan pelayanan secara holistik.

\section{DAFTAR PUSTAKA}

Afiyanti, Y. \& Rachmawati, I.N. (2014). Metodologi penelitian kualitatif dalam riset keperawatan. Jakarta: PT Raja Grafindo Persada.

Arbabisarjou, A., Karimzaei, T., Jamalzaei, A. (2014). The perception of biological experience in patients with major Thalassemia: a qualitative research. Glob. J. Health Sci. 7, 79-87. doi:10.5539/gjhs.v7n1p79

Asyanti, S. (2013). Dinamika Permasalahan Pada Orang Tua yang Memiliki Anak dengan Penyakit Kronis dan Tantangannya dalam Mengantarkan Anak Menjadi 
Pribadi yang Lebih Sehat dan Berkarakter Tangguh. Diakses dari https://publikasiilmiah.ums.ac.id/bitstream /handle/11617

Baghianimoghadam, M.H., Sharifirad, G., Rahaei, Z., Baghianimoghadam, B., Heshmati, H. (2011). Health related quality of life in children with thalassaemia assessed on the basis of SF-20 questionnaire in Yazd, Iran: a case-control study. Cent. Eur. J. Public Health 19, 165169.

Cappellini, M.D., Cohen, A., Porter, J., Taher, A., Viprakasit, V. (2014). Guidelines for the Management of Transfusion Dependent Thalassaemia (TDT). Thalassaemia International Federation.

Friedman, M.M., Bowden, V.R., \& Jones, E.G. (2013). Keperawatan keluarga; riset, teori dan praktek.edisi kelima. (Hamid, A.Y., Sutama, A., Subekti, NB., Yulianti, D dan Herdina, N; alih bahasa). Jakarta: EGC.

Hatzmann, J., Peek, N., Heymans, H., Maurice-Stam, H., Grootenhuis, M. (2014). Consequences of caring for a child with a chronic disease: Employment and leisure time of parents. J. Child Health Care Prof. Work. Child. Hosp. Community 18, 346357. DOI:10.1177/1367493513496668.

Hockenberry, M. J., Wilson, D., \& Wong, D. L. (2011). Wong's nursing care of infants and children e.t $9^{\text {th }}$. Canada: Mosby Elsevier.

Indriati, G. (2011). Pengalaman Ibu dalam Merawat Anak dengan Thalassemia di Jakarta. Diakses dari http://lib.ui.ac.id

Mariani, D. (2011). Analisis faktor yang mempengaruhi kualitas hidup anak thalassemia beta mayor di RSU Kota Tasikmalaya dan Ciamis.Universitas Indonesia. Diperoleh dari http://lib.ui.ac.id

Moleong, L.J. (2014). Metodelogi penelitian kualitatif, edisi revisi. Bandung: PT. Remaja Rosdakarya.

Potter, P.A., \& Perry, A.G. (2009). Fundamental of nursing. Singapore: Elsevier Ltd.

Rachmaniah, D. (2012). Pengaruh Psikoedukasi Terhadap Kecemasan dan koping Orangtua dalam Merawat Anak dengan Thalassemia Mayor di RSU
Kabupaten Tangerang Banten. Diakses dari http://lib.ui.ac.id

Sapountzi-Krepia, D., Roupa, Z., Gourni, M., Mastorakou, F., Vojiatzi, E., Kouyioumtzi, A., Van Shell, S. (2006). A Qualitative Study on the Experiences of Mothers Caring for Their Children with Thalassemia in Athens, Greece. J. Pediatr. Nurs. Nurs. Care Child. Fam. 21, 142-152. doi:10.1016/j.pedn.2005.06.017

Surapolchai, P., Satayasai, W., Sinlapamongkolkul, P., Udomsubpayakul, U. (2010). Biopsychosocial predictors of health-related quality of life in children with thalassemia in Thammasat University Hospital. J. Med. Assoc. Thail. Chotmaihet Thangphaet 93 Suppl 7, S65-75.

Wong, D.L., Hockenberry-Eaton, M., Wilson, D., Wilkelstein, M.L., \& Schwartz, P. (2009). Buku Ajar Keperawatan Pediatrik. Edisi 6 Volume 1.Alih bahasa Andry Hartono, Sari Kurnianingsih, Setiawan. Jakarta: EGC. 